\title{
Learning by engaging: connecting with our students to keep them active and attentive in online classes
}

\author{
Lynn Gribble \\ University of New South Wales, Australia \\ Janis Wardrop \\ University of New South Wales, Australia
}

Keywords: engaging; student connection; emojis; Covid-19.

\section{The challenge}

Our challenge was to take a large postgraduate course, comprised of $90 \%$ international students, online while maintaining student engagement. The course was based on constructivist principles (after Piaget, 1973, and Vygotsky, 1978), requiring the students to actively engage in their learning with a mix of activity-based workshops (rather than tutorials) and large group case study discussion (rather than lectures). As a commencing course in the programme, one of the central missions of our course is to encourage and equip students to be successful in a learning environment that requires greater engagement and self-regulatory behaviour. Many of these students have previous experience with largely didactic approaches to learning, where the teacher at the front of the room is the expert to be listened to. Now the challenge we confronted was not just the familiar one of introducing students to a more active and engaged method of learning but of doing so in an online classroom. We also knew that access to technology and reliable internet connections would be additional issues that we would need to accommodate.

\section{The response}

We wanted our students to have the opportunity to have a voice in the classroom and to interact and engage with us and the materials as they would in a face-to-face environment. Their personal context was equally important as many students would have been 
experiencing anxiety, along with a sense of loss and dislocation, irrespective of whether than had returned to their home country as the pandemic hit or were now effectively marooned in Australia (Salmi, 2020; Mushquash and Grassia, 2021). Hence building a sense of community and connection within the cohort was an imperative. Quickly we turned our attention to using tools within our Learning Management System (LMS), Moodle, or any system that could be deployed through a one click link. This was to ensure that the student cognitive load to learn was not consumed by learning, using, or accessing complex technology (Moore, 1993).

To provide students with a sense of connection and engagement within the cohort we delivered classes synchronously. While students were encouraged to participate in discussions using microphone and video, it was quickly apparent that (for whatever reason) they were more confident contributing via the chat function. Thus, the online chat function replaced the in-person classroom discussions allowing us to maintain the interactive and iterative approach to learning that is a feature of constructivist approaches.

Within the chat panel, emojis created the opportunity to welcome and acknowledge each student quickly as they arrived and departed. More importantly they helped break down the pre-conceived formal barriers of teacher and student, building an informal and safe learning environment where students developed the confidence to ask questions and voice their opinions (albeit in the chat box), as they would during a face-to-face class. Anecdotal feedback from students suggests they appreciated the approach. As we teach multiple subjects, students now look for these practices when they next meet us. Furthermore, students are encouraging other teachers to employ similar tactics. The use of emojis is familiar to the students and part of the language they use when texting friends informally. By using emojis we can bring their language into the classroom and reduce the formality. We encouraged the use of emojis in the chat function as a feedback channel, since the students could and would quickly send an emoji to let us know if they understood or had questions and to indicate how they were feeling as classes started and ended. As a feedback mechanism, teachers issued stars for good answers, coffees for supporting others, and constellations of stars for exemplary answers; the talking head was given to any well-considered answer. 
In order to keep students engaged we recognised that asking them to do things focused them on the lesson at hand and kept them busy interacting with us. Interactively using polls via the Socrative $\AA^{\circledR}$ platform enabled us to support students emotionally and initiate conversations about their needs and concerns. Rather than merely measuring conceptual understanding of course material, we measured student sentiment enabling us to provide emotional support in a time when students may have felt disconnected or lost in their digital learning environment. The poll data was 'mine-able', meaning we could ensure our communications during and following class spoke to their reported needs and concerns. These polls ask students to respond to questions with multiple choice answers, such as 'I'm lost', 'I'm confident', or 'I think I'm okay'.

\section{Recommendations}

Technology does not have to be faceless or emotionless. It can enable connection and engagement, but it must match and start where the student is. Emojis are easily accessible, while teaching to 'cut and paste into the chat box' and encouraging students to participate in an open dialogue during class is easy to integrate into the framework of your class. Keeping the student's attention can be achieved through expectations of interaction. By extending the use of polls beyond their traditional use of content confirmation to realtime pulse checks of student engagement and emotional commitment to learning we were able to build a culture of care through acknowledging the student and their unique situation. Reflecting on how we would interact in a face-to-face classroom, we encourage the use of tools, already available in existing LMS technology, to provide interactive opportunities. These are simple to use and can be enacted just as you might ask 'hands up .... In a physical classroom we look for twitches and phone scrolling to provide feedback on engagement; online, we monitor the speed of response rates when polling as well as the chat functions to keep the students interacting. While the students might now be keyboard warriors, they are not faceless and emotionless; they are waiting to be drawn into text-style conversation and interaction with you just as they are with their peers.

\section{References}


Moore, M. J. (1993) 'Three types of interaction', in Harry, K., John, M. and Keegan, D. (eds.) Distance education theory. New York: Routledge, pp.19-24.

Mushquash, A. R. and Grassia, E. (2021) 'Coping during COVID-19: examining student stress and depressive symptoms', Journal of American College Health, https://doi.org/10.1080/07448481.2020.1865379.

Piaget, J. (1973) Main trends in psychology. London: Allen and Unwin.

Salmi, J. (2020) COVID's Lessons for Global Higher Education. Available at: https://www.luminafoundation.org/wp-content/uploads/2020/11/covids-lessons-forglobal-higher-education.pdf (Accessed: 22 June 2021).

Vygotsky, L. S. (1978) Mind in society: the development of higher psychological processes. Cambridge, MA: Harvard University Press.

\section{Author details}

Lynn Gribble (SFHEA) has taught management to large classes of Master of Business Administration and Master of Commerce students for 15 years and is a leader in online learning. She has pioneered the use of voice recordings, audience response platforms, and learning analytics to personalise every interaction with her students, increasing both their engagement and learning outcomes.

Janis Wardrop (SFHEA) is an academic leader, educational change agent, and commentator on management education, and business ethics and governance. With 15 years' experience in academia as both lecturer, programme leader, and manager, her expertise lies in adopting a holistic approach to curriculum design. She is committed to providing UNSW students with the best educational outcomes to establish themselves as global leaders. 